\title{
Co-occurring Synechococcus ecotypes occupy four major oceanic regimes defined by temperature, macronutrients and iron
}

\author{
Jill A Sohm ${ }^{1,4}$, Nathan A Ahlgren ${ }^{1,2,4}$, Zachary J Thomson ${ }^{2}$, Cheryl Williams ${ }^{2}$, \\ James W Moffett ${ }^{1}$, Mak A Saito ${ }^{3}$, Eric A Webb ${ }^{1}$ and Gabrielle Rocap ${ }^{2}$ \\ ${ }^{1}$ Department of Biological Sciences, University of Southern California, Los Angeles, CA, USA; ${ }^{2}$ School of \\ Oceanography, University of Washington, Seattle, WA, USA and ${ }^{3}$ Marine Chemistry and Geochemistry \\ Department, Woods Hole Oceanographic Institution, Woods Hole, MA, USA
}

\begin{abstract}
Marine picocyanobacteria, comprised of the genera Synechococcus and Prochlorococcus, are the most abundant and widespread primary producers in the ocean. More than 20 genetically distinct clades of marine Synechococcus have been identified, but their physiology and biogeography are not as thoroughly characterized as those of Prochlorococcus. Using clade-specific qPCR primers, we measured the abundance of 10 Synechococcus clades at 92 locations in surface waters of the Atlantic and Pacific Oceans. We found that Synechococcus partition the ocean into four distinct regimes distinguished by temperature, macronutrients and iron availability. Clades I and IV were prevalent in colder, mesotrophic waters; clades II, III and X dominated in the warm, oligotrophic open ocean; clades CRD1 and CRD2 were restricted to sites with low iron availability; and clades XV and XVI were only found in transitional waters at the edges of the other biomes. Overall, clade II was the most ubiquitous clade investigated and was the dominant clade in the largest biome, the oligotrophic open ocean. Co-occurring clades that occupy the same regime belong to distinct evolutionary lineages within Synechococcus, indicating that multiple ecotypes have evolved independently to occupy similar niches and represent examples of parallel evolution. We speculate that parallel evolution of ecotypes may be a common feature of diverse marine microbial communities that contributes to functional redundancy and the potential for resiliency.
\end{abstract}

The ISME Journal (2016) 10, 333-345; doi:10.1038/ismej.2015.115; published online 24 July 2015

\section{Introduction}

Microbes have vital roles in marine biogeochemical cycles, and describing their biogeography is critical to our understanding of where and how particular taxa contribute to these cycles (for example, the carbon cycle). As marine microbes carry out nearly half of primary production on earth, understanding the diversity and activity of phytoplankton is paramount to informing global models (Field et al., 1998). The most abundant of these phytoplankton are the picocyanobacteria, which are broadly classified into the genera Prochlorococcus and Synechococcus based on their size and photosynthetic pigments: Synechococcus $(0.6-2 \mu \mathrm{m})$ are slightly

Correspondence: EA Webb, Department of Biological Sciences, University of Southern California, 3616 Trousdale Pkwy, Los Angeles, CA 90089, USA.

or G Rocap, School of Oceanography, University of Washington, Box 357940, Seattle, WA 98195, USA.

E-mail: eawebb@usc.edu or rocap@ocean.washington.edu

${ }^{4}$ Co-authors.

Received 10 November 2014; revised 18 March 2015; accepted 19 May 2015; published online 24 July 2015 larger than Prochlorococcus $(0.6-0.8 \mu \mathrm{m})$ and Synechococcus possess light-harvesting phycobilisomes while Prochlorococcus does not and instead has divinyl chlororophyll $a$ and $b$ (Waterbury et al., 1986; Coleman and Chisholm, 2007; Scanlan et al., 2009). Where the two coexist in the open ocean, Prochlorococcus are frequently more abundant than Synechococcus, often by 10 -fold or more. However, Synechococcus can be temporally or regionally important contributors to carbon fixation, as they can be seasonally dominant (Flombaum et al., 2013) and their larger cell size means they can fix an order of magnitude more carbon than Prochlorococcus cells (Jardillier et al., 2010). Synechococcus is also present in a wider variety of environments-openocean and coastal waters from tropical to polar environments (Waterbury et al., 1986; Zwirglmaier et al., 2007; Huang et al., 2011)—suggesting that the genus Synechococcus encompasses a wider range of physiological diversity.

Considerable genetic and genomic diversity within these two genera (Ferris and Palenik, 1998; Moore et al., 1998; Fuller et al., 2003; Palenik et al., 2006; Coleman and Chisholm, 2007; Kettler et al., 2007; 
Dufresne et al., 2008; Scanlan et al., 2009; Ahlgren and Rocap, 2012) suggests that each genus contains subpopulations with physiological differences that could allow them to occupy different environments. In fact, at least six phylogenetic clades in Prochlorococcus have been shown to represent ecotype subpopulations that differ in physiology and occupy distinct niches in the oceans (Moore et al., 1998; Johnson et al., 2006; Coleman and Chisholm, 2007; Martiny et al., 2009). This niche differentiation apparently occurred in a successive or stepwise manner as basal Prochlorococcus clades are better adapted to low-light conditions, a more recently emerged lineage (LLI) can be found throughout the water column, and the most derived clades are high-light adapted. There is evidence of further divergence within the high-light lineage, resulting in ecotypes that occupy different temperature and nutrient regimes (Johnson et al., 2006; Coleman and Chisholm, 2007; Martiny et al., 2009; Malmstrom et al., 2012). Such integration of information about the biogeographic and phylogenetic relatedness of ecotypes provides insight into evolutionary processes underlying niche differentiation in marine microbes.

In contrast, there is no clear model describing how the phylogeny of the marine Synechococcus group relates to the physiology or ecology of clades, in part because there are $>20$ clades (Ahlgren and Rocap, 2006; Huang et al., 2011; Mazard et al., 2012a) and only a few recognized adaptations described for cultured isolates. Examples include differences in light-harvesting phycobilisome pigments and structures, and the capacity to alter phycobilisomes to capture different wavelengths of light (Palenik, 2001; Ahlgren and Rocap, 2006; Six et al., 2007), differing abilities to grow on nitrate $\left(\mathrm{NO}_{3}^{-}\right)$ (Moore et al., 2002; Ahlgren and Rocap, 2006; Fuller et al., 2006), or on different organic P sources (Moore et al., 2005; Mazard et al., 2012b). While identification of such traits is valuable, in many cases physiological information is available for only a subset of clades currently in culture and several clades do not yet have cultured representatives.

Variation in genome content among 10 cultured isolates is also suggestive of ecological differences between Synechococcus clades (Palenik et al., 2006; Dufresne et al., 2008; Scanlan et al., 2009). For example, specific gene differences explain in vivo variations in pigment composition and $\mathrm{N}$ utilization (Palenik et al., 2006; Six et al., 2007; Dufresne et al., 2008; Scanlan et al., 2009). In addition, Synechococcus strains have different complements of predicted Fe sensing and acquisition genes (Palenik et al., 2006; Rivers et al., 2009; Scanlan et al., 2009). However, as is the case with physiological data from cultures, it is difficult to predict the realized niches and biogeography of Synechococcus clades solely from their genomic potential.

Molecular detection of Synechococcus clades in situ has provided valuable insight into their biogeography and factors controlling their distributions (Fuller et al., 2003, 2006; Zwirglmaier et al., 2007, 2008; Tai and Palenik, 2009). Clone libraries of cyanobacterial genes (for example, the $16 \mathrm{~S}-23 \mathrm{~S}$ internally transcribed spacer (ITS), rpoC1, narB and pet $B$ ) have been used to identify the breadth of the diversity of natural communities (Toledo and Palenik, 1997; Rocap et al., 2002; Paerl et al., 2008; Choi and Noh, 2009; Huang et al., 2011; Mazard et al., 2012a), while assays designed to measure the abundance of specific clades have provided quantitative information about their distributions (Fuller et al., 2006; Zwirglmaier et al., 2007, 2008; Ahlgren and Rocap, 2012; Ahlgren et al., 2014; GutierrezRodriguez et al., 2014). The most comprehensive of these latter studies, in terms of global biogeography, revealed an unprecedented view of clades that are preferentially more abundant in cold (clades I and IV) vs warmer (clade II) coastal and shelf habitats, concurrent with latitude. Additionally, this study identified clade III as an oligotroph restricted to open ocean waters (Zwirglmaier et al., 2008).

Subsequent studies have expanded the known genetic and genomic diversity of Synechococcus (Huang et al., 2011; Mazard et al., 2012a), so there is an opportunity to update our view of clade biogeography, particularly for newly described clades not detected by previous assays. Additionally, while it is clear that temperature and macronutrient availability are strong drivers of Synechococcus and Prochlorococcus clade niche adaptation, these environmental parameters often do not fully explain the variance in clade abundances (for example, Johnson et al., 2006; Zwirglmaier et al., 2007, 2008), suggesting that other biotic or abiotic factors and interactions are also important in the niche partitioning of marine cyanobacteria. Specifically, trace metals like iron (Fe) and cobalt (Co) are hypothesized to influence niche adaptation of cyanobacteria ecotypes (Palenik et al., 2006; Zwirglmaier et al., 2008). For example, two new Prochlorococcus clades have been identified that are apparently adapted to high nutrient, low chlorophyll (HNLC) regions known to be Fe limited (Rusch et al., 2010; West et al., 2011), and Fe and cobalt are implicated in shaping Synechococcus clade composition in the tropical Pacific (Ahlgren et al., 2014). However, because trace metals have not been measured alongside Prochlorococcus or Synechococcus clade abundances on a global scale, their importance in shaping niche adaptation of ecotypes has not been clarified.

To elucidate the ecology of Synechococcus populations, we have mapped the distribution of 10 Synechococcus clades in the global surface ocean using clade-specific qPCR assays targeting the 16S-23S rDNA ITS region (Ahlgren and Rocap, 2012). These data were quantitatively related to environmental parameters including temperature, macronutrients, and the trace metal Fe to discern how these variables affect the distribution of Synechococcus clades and to better define their 
specific niches. Our study expands upon previous Synechococcus biogeography surveys (Fuller et al., 2006; Zwirglmaier et al., 2007, 2008; Tai and Palenik, 2009; Mella-Flores et al., 2011; Mazard et al., 2012a) by measuring four additional clades (XV, XVI, CRD1 and CRD2) that were not specifically enumerated previously (Ahlgren and Rocap, 2012) and concurrently measuring dissolved $\mathrm{Fe}$ for samples from four out of nine cruises. Finally, the distinct niches of clades inferred from biogeographic surveys were examined in light of their phylogenetic relatedness to investigate how adaptation to shared niches relates to the broader evolutionary history of marine Synechococcus.

\section{Materials and methods}

Samples were collected on nine research cruises. Details of cruise locations, dates, parameters measured and source of data (if previously published) are listed in Supplementary Table S1. Temperature and salinity data were extracted from conductivity, temperature, depth sensor data taken at the time of sampling. Macronutrients were measured with standard colorimetric methods (Strickland and Parsons, 1968). For four of the nine cruises dissolved Fe (Fe that passes through a $0.4-\mu \mathrm{m}$ filter, hereafter simply referred to as $\mathrm{Fe}$ ) was measured using trace metal clean protocols (Chappell et al., 2012; Noble et al., 2012) from the corresponding water columns (same cruises, stations and depths) for which DNA samples were taken (Supplementary Table S1, Supplementary Figure $\mathrm{S} 1)$. In total, Fe was measured at $53 \%$ of the surface stations used in our analyses.

Abundances of 10 Synechococcus clades were measured using clade-specific qPCR assays applied to DNA extracted from $100 \mathrm{ml}$ of filtered seawater as described in Ahlgren and Rocap (2012) except that for some samples DNA was extracted from 1 to 21 of filtered seawater (volumes were recorded and accounted for in the calculation of clade cells $\mathrm{ml}^{-1}$ ). All standards and samples were run in triplicate and melt curves showed no evidence of non-specific amplification. When triplicate reactions had poor replication $(\geqslant 3 \%$ standard error) outliers were identified and removed using the Q test (Dean and Dixon, 1951). We note that $>20$ Synechococcus clades have been identified using a variety of different loci (Ahlgren and Rocap, 2012); however, many of those not investigated with our qPCR assays are rarely observed in clone libraries, are restricted to estuarine or polar/subpolar waters, or are not represented by enough sequences to confidently design discriminative primers (Zwirglmaier et al., 2008; Huang et al., 2011).

Linear correlations (Pearson's $r$ ) were computed between $\log (x+1)$ clade abundances to investigate patterns of clade co-occurrence. Local similarity analysis (LSA) (Ruan et al., 2006) was used to investigate linear correlations between environmental factors and clade abundances using two data sets: (1) samples that had associated temperature, $\mathrm{NO}_{3}^{-}$and $\mathrm{PO}_{4}^{3-}$ data or (2) samples that also had Fe data. Spearman rank correlations were computed to investigate non-linear relationships between clade abundances and environmental factors. For each clade, box and whisker plots were generated for temperature, $\mathrm{NO}_{3}^{-}, \mathrm{PO}_{4}^{3-}, \mathrm{Fe}$ and clade richness (the number of Synechococcus clades detected) for samples where that clade was detected. Significance levels for multiple pairwise linear and Spearman tests and pairwise $t$-tests of environmental parameters means were corrected with the Benjamini and Hochberg procedure $(P<0.05)$ (Benjamini and Hochberg, 1995).

Non-metric multidimensional scaling analyses were conducted with the package vegan in $R$ (Oksanen et al., 2012) on the data sets with and without Fe. Bray-Curtis dissimilarities were computed using Wisconsin double standardization of $\log (\mathrm{x}+1)$ transformed clade abundances. Samples in the without $\mathrm{Fe}$ analysis clustered into four groups with dissimilarities of $\leqslant 0.5$, and this grouping of samples was significantly supported by analysis of similarities $(P<0.001,999$ permutations). Significant correlation of environmental parameters to sample ordination was tested with the envfit function in vegan. Significant relationships were also supported by Permutational Multivariate Analysis of Variance Using Distance Matrices as computed with the function adonis using 1000 permutations $(P<0.001$ for each correlation to temperature, $\mathrm{NO}_{3}^{-}$and $\mathrm{PO}_{4}^{-3}$ in the analysis without $\mathrm{Fe}$ data and $P<0.01$ for the correlation to $\mathrm{Fe}$ in the analysis with $\mathrm{Fe}$ data).

\section{Results and Discussion}

\section{Relationship between qPCR and cell counts}

We analyzed 301 samples from 92 stations sampled on 9 research cruises in the Atlantic and Pacific Oceans from 2002 to 2010. To determine how well the abundance of these 10 clades (as measured by qPCR) represents the total abundance of Synechococcus present at each station, the sum of the qPCR clade abundances was compared with Synechococcus abundance from either microscope counts (Waterbury et al., 1986) or flow cytometry (Marie et al., 2005), when available $(n=96)$. The data cluster around a line with a slope of $0.84\left(R^{2}=0.54\right)$, and $80 \%$ of samples are less than four-fold different between counts and summed qPCR indicating that, for the majority of samples for which we have cell count data, most of the Synechococcus present are accounted for with the 10 clades investigated (Figure 1a). Small overestimation observed in our data and other qPCR assays of natural samples may be due in part to natural variation in genome copies per cell (Zinser et al., 2007; Tai and Palenik, 2009; Ahlgren and Rocap, 2012). Notably, in five samples total cell counts were more than 10-fold higher than the sum of the qPCR clade abundances, suggesting 


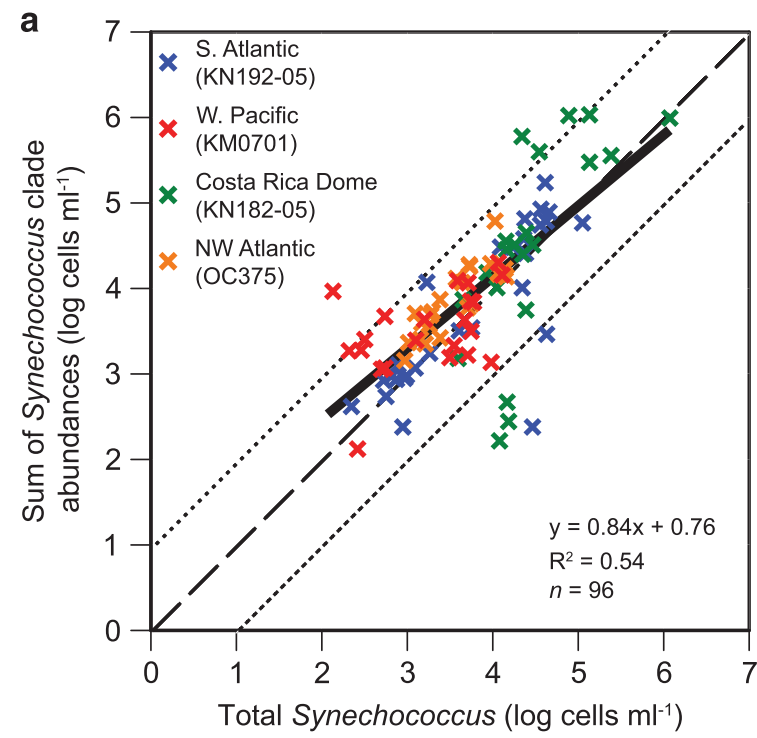

b

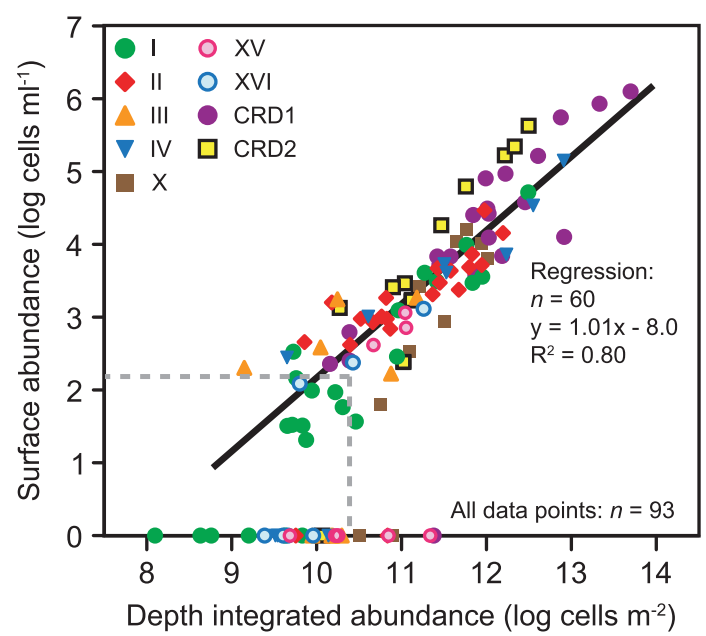

Figure 1 Validity of qPCR methodology and use of surface values in analysis. (a) Comparison of total Synechococcus abundance (determined with microscope counts or flow cytometry (FCM)) to the sum of all 10 Synechococcus clade abundances measured by qPCR. Points are color coded by region and research cruise (Supplementary Table S1). Because the limits of detection for measuring total Synechococcus by FCM or microscopy or for measuring individual clades qPCR assays are all about 100 cells $\mathrm{ml}^{-1}$, samples where either FCM/microscopy counts $(n=6)$ or summed qPCR results $(n=4)$ were below 100 cells $\mathrm{ml}^{-1}$ were excluded. The dashed line depicts the 1:1 line, dotted lines depict 10:1 and 1:10 lines, and the solid line depicts the linear regression of the data. Most samples (80\%) were within 4-fold of the 1:1 line. (b) Water column integrated abundance vs surface abundance of Synechococcus clades for all cruises where profiles were available (TN-224, KM0405, KM0701, KN182-05, OC375 and KN192-05, see Supplementary Table S1). Trapezoidal integration was used to generate water column values down to $150 \mathrm{~m}$ for 34 depth profiles. The horizontal dashed line indicates the median detection limit for the qPCR assays (150 cells $\mathrm{ml}^{-1}$ ), and the vertical dashed line depicts a corresponding lower limit for depth-integration values assuming cells are at the 150 cells $\mathrm{ml}^{-1}$ detection limit in a water column of $150 \mathrm{~m}\left(2.3 \times 10^{10}\right.$ cells $\left.\mathrm{m}^{-2}\right)$. The regression only includes data points where surface abundances were above the detection limit. the presence of additional Synechococcus clades not detected by our qPCR primers. These locations may harbor novel clades and be productive targets for future isolation efforts.

Horizontal vs vertical partitioning of Synechococcus clades Previous surveys indicate that Synechococcus partition the oceans more strongly along the horizontal scale than vertically with depth (Fuller et al., 2003, 2006; Zwirglmaier et al., 2007, 2008; Choi and Noh, 2009; Huang et al., 2011; Mazard et al., 2012a), and we found similar trends in our study. Globally, surface clade abundance was strongly correlated to depth integrated clade abundances (Figure 1b); hence, the Synechococcus community structure at the surface appears to generally be representative of the community at lower depths. Notable exceptions include six instances where a clade was not detected in the surface but had depth integrated abundances significantly above the limit of detection (Figure 1b). These cases were primarily attributed to clade $\mathrm{XV}$, which has been found at higher abundances below surface waters (Ahlgren et al., 2014). Most other anomalies from the otherwise strong relationship between surface and depth integrated abundance represent a clade detected in a subsurface sample just above the limit of detection but not detected in surface waters (for example, see Supplementary Figure S2: clade I in station 3 and clade III in station 13). These occurrences result in depth integrated abundances below the theoretical limit of detection and thus represent artifacts of detecting populations near the limit of detection rather than an indication that surface populations were not representative of those at depth.

Specifically, in the North Pacific, clade composition was fairly uniform with depth but changed dramatically with latitude (Figure 2), from domination by clades I and IV above $37^{\circ} \mathrm{N}$, to clade II in subtropical waters, and then to clade CRD1 south of $\sim 20{ }^{\circ} \mathrm{N}$. A similar shift from clade II to CRD1 throughout the water column was seen from the western to eastern basins in the South Atlantic (Supplementary Figure S2, station 3 vs station 13). In contrast, vertical partitioning of clades was not observed in these transects, as clade abundance almost always decreased with depth along with total Synechococcus abundance (Figure 2; Supplementary Figure S2). In summary, our data indicate surface clade abundances are generally representative of deeper populations. We therefore focused on studying the global biogeography of surface populations for which we had a broader distribution of samples.

The biogeography, co-occurrence and niche adaptation of Synechococcus clades

Synechococcus was found widely distributed in surface waters of the global ocean, detected with at least one set of qPCR primers at $93 \%$ of stations (Figure 3 ). At the majority of stations (55\%) a single 

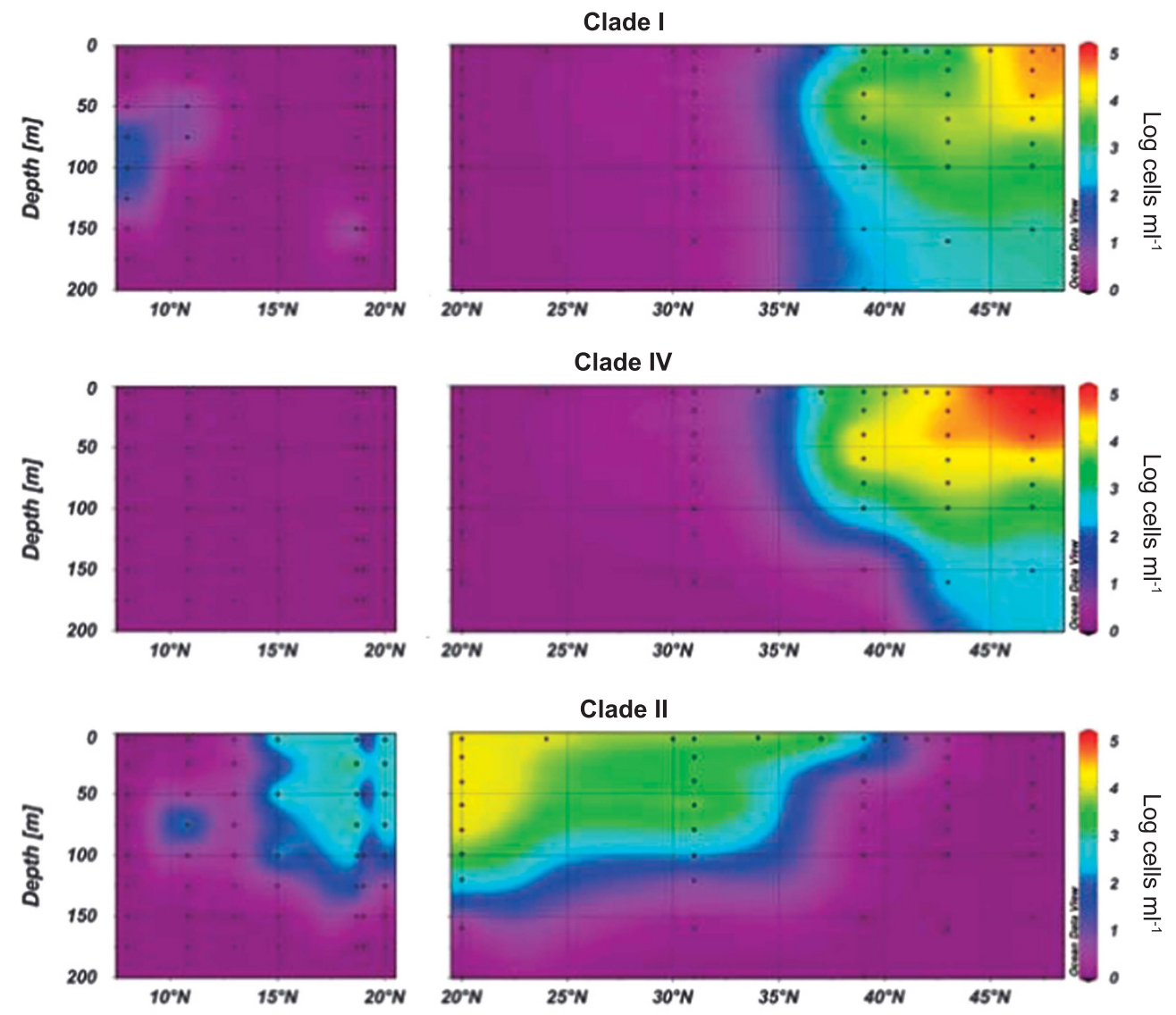

Clade II

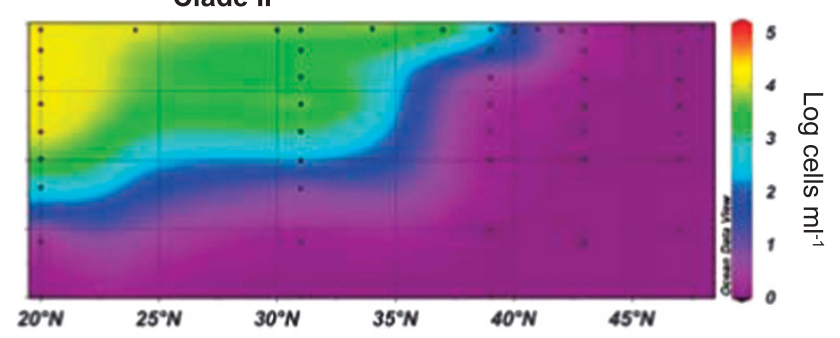

Clade CRD1
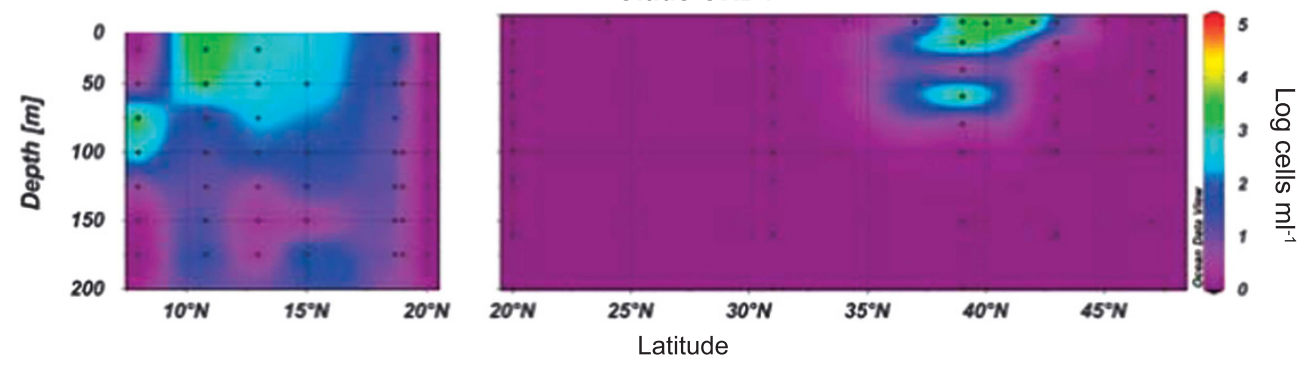

Figure 2 Sections from two cruises in the North Pacific (left, R/V Kilo Moana, February 2004, $202{ }^{\circ}$ E; right, R/V Thompson, September 2008, $208^{\circ} \mathrm{E}$ ) showing abundance of dominant clades in the region with depth (clades III and X, not shown, were often present with clade II, but in lower abundance). The transition from clades I and IV in the subarctic to clade II in subtropical waters to clade CRD1 in the equatorial upwelling region is clearly seen both at the surface and at lower depths. Clade CRD1 is also present at the surface where the population transitions from clades I and IV to clade II at $\sim 40{ }^{\circ} \mathrm{N}$.

clade made up $>80 \%$ of the total Synechococcus population (Figure 3, Supplementary Figure S3). Nevertheless, multiple Synechococcus clades often co-occurred in surface waters, with at least three clades detected at $43 \%$ of stations. Four distinct groups of frequently co-occurring clades emerged from global distribution patterns and were supported by significant linear correlations between clade abundances (Figure 4a; see Supplementary Table S2 for numerical values ): clades I and IV; II, III and X; CRD1 and CRD2; and XV and XVI. Members of Clade VIII are generally found in euryhaline or estuarine waters (Dufresne et al., 2008; Huang et al., 2011) and unsurprisingly were not detected in our oceanic samples.
Ordination of samples based on clade composition resulted in four significantly distinct clusters, each dominated by a different group of clades (Figure 5). These sites were significantly correlated to gradients in temperature, nutrients and Fe (Figure 5). Thus, each group of clades occupied a distinct marine biome or habitat: (1) clades I and IV dominated in cold, nutrient-rich waters ('cold, high nutrient'); (2) clades II, III and X were dominant in warm, oligotrophic, open-ocean habitats in the tropical and subtropical oceans ('warm, low nutrient'); (3) clades CRD1 and CRD2 ('low Fe') were most successful in low Fe waters that overlap with previously defined HNLC provinces (Martin et al., 1991; Fung et al., 2000) including equatorial upwelling regions and 


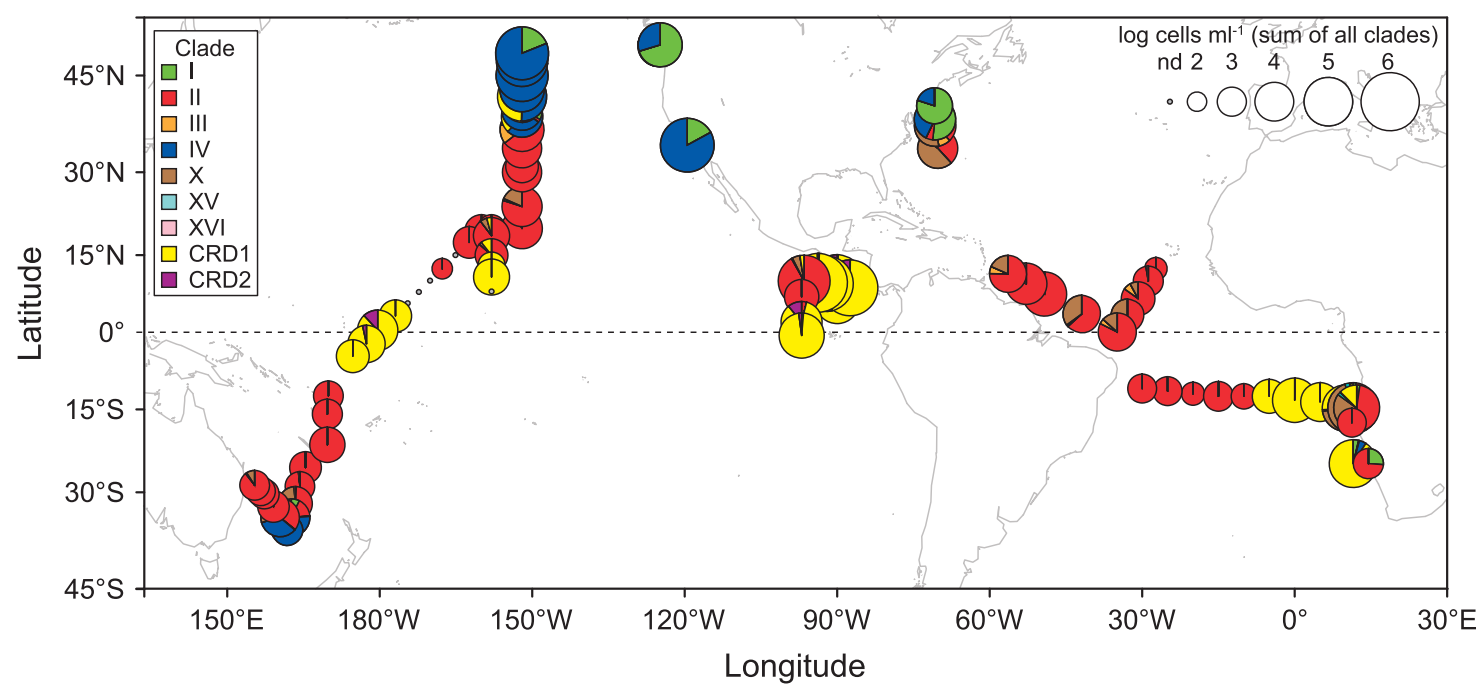

Figure 3 Global map of Synechococcus clade distributions in surface waters. Pie charts depict the relative abundance of each clade, and the radius of each pie chart is scaled to the sum of clade abundances at that location (scale at top right, log cells $\mathrm{ml}^{-1}$ ). Small gray circles indicate stations where none of the 10 clades were above the limits of detection of the assays, generally $\sim 100 \mathrm{cells} \mathrm{ml}^{-1}$ ('nd'). Maps of individual clade abundances are shown in Supplementary Figure S3.

a

Pearson correlations $(r)$ between

Synechococcus clade abundances

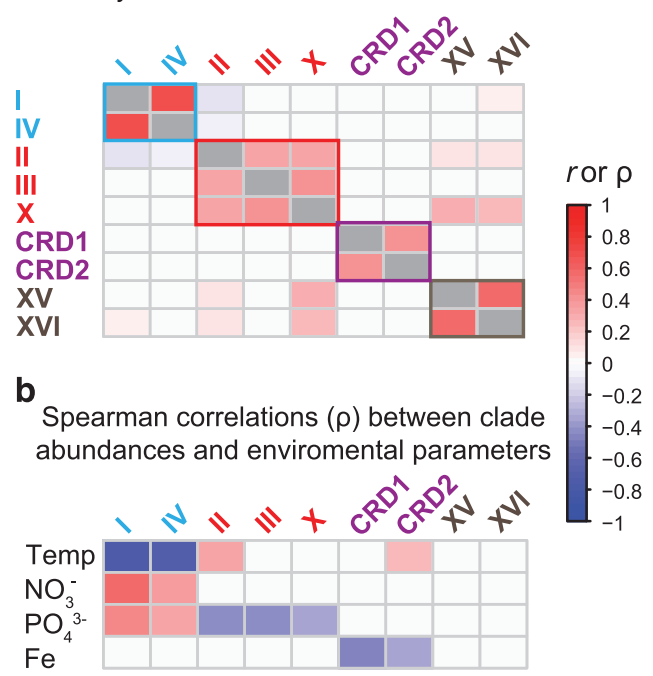

Figure 4 (a) Linear Pearson's correlation coefficients $(r)$ between log transformed Synechococcus clade abundances and (b) Spearman correlation coefficients $(\rho$ ) between Synechococcus clade abundances and environmental parameters. Only significant correlations $(P<0.05)$ are shown. Clade names are colored according to the four major groups of co-occurring clades that are evident from the linear correlations (these groups are also highlighted by corresponding colored boxes in the matrix).

North Pacific sites; and (4) clades XV and XVI occurred at low abundances and were only detected at ecotone sites with intermediate conditions that often occurred near junctions of biomes ('transitional').

Clades I and IV were highly correlated to each other (Figure 4a) and were mainly restricted to high latitude open ocean sites and temperate coastal zones, as has been previously well described
(Zwirglmaier et al., 2008; Tai and Palenik, 2009). These sites are typified by significantly higher nutrient levels and colder temperatures (Figures 4 and 6). Linear LSA (Supplementary Figure S4) and non-linear Spearman rank correlations (Figure 4b) confirm positive and negative relationships of clades I and IV to macronutrients and temperature, respectively. The latter agrees with recent characterization of clade I strains that exhibit greater tolerance to cold temperatures than those of clade II (Pittera et al., 2014). Clades I and IV had higher mean abundances than clades II, III and X (although only significantly higher for clade III, $P<0.05)$ and higher maximum abundances than clades II and III (Supplementary Table S3) as they were typically found in waters that support higher total Synechococcus abundance.

The relative abundances of clades I and IV have been shown to vary between ocean regions, but controls on this ratio are unclear (Zwirglmaier et al., 2008). Temporal studies at a coastal site suggest that clade I can take advantage of rapid increases in nutrients, while clade IV is more ubiquitous yearround (Tai and Palenik, 2009). Genomic, physiological and transcriptomic studies suggest that perhaps these clades are better adapted to fluctuating metal conditions in coastal habitats (Palenik et al., 2006; Stuart et al., 2009). Our analysis appears to show a lower Fe range for clade I (Figure 6c); however, it is important to note that $\mathrm{Fe}$ was not measured in our study at sites frequently dominated by clades I and IV (Supplementary Figure S1) so we cannot be conclusive about their Fe niches. Although both clades I and IV exhibit a low Fe range in our data set (Figure 6c) and are dominant in the subarctic, HNLC North Pacific (Martin et al., 1991; Fung et al., 2000), we suspect that the actual Fe range for both clades I and IV is broader than depicted here given that they 
a Ordination of samples in relation to

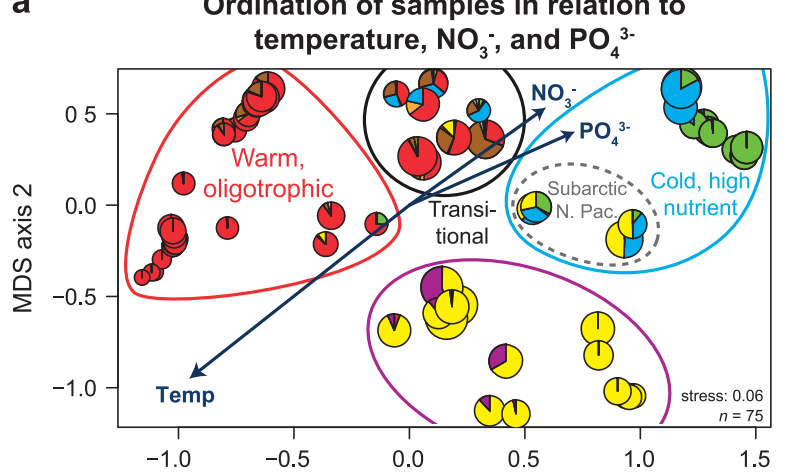

b Ordination of samples in relation to

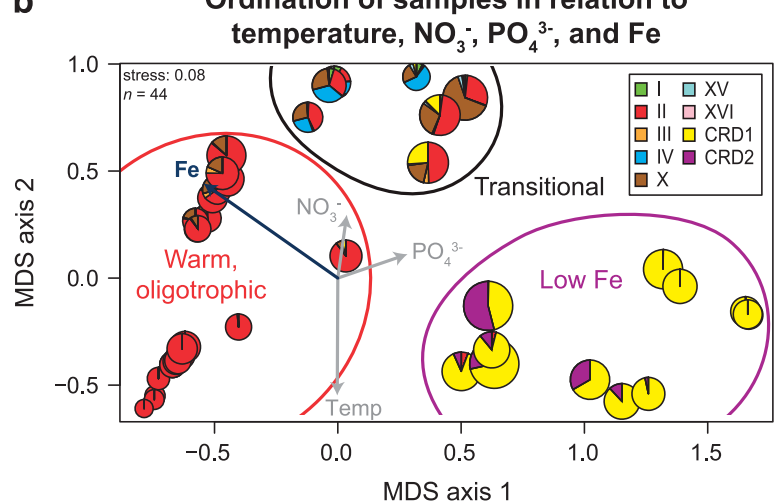

Figure 5 Non-metric multidimensional scaling (nMDS) ordination of samples according to Bray-Curtis dissimilarity calculated from clade abundances. Pie charts depict relative clade composition and total summed abundance as in Figure 3 for each sample. (a) Analysis with temperature and nutrients ( $n=75$ samples). (b) Analysis of samples with temperature, nutrient and Fe data $(n=44)$. Note that samples dominated by clades I and IV are absent from (b) because Fe was not measured at these sites. Solid lines indicate clusters of samples where samples within each cluster have Bray-Curtis dissimilarities of $\leqslant 0.5$, and this clustering of samples was supported by analysis of similarities $(P<0.01)$. Clusters are classified into four regime types defined by their biogeography and environmental parameter ranges. Parameters significantly correlated to sample ordination are depicted in blue $(P<0.05)$. A dashed gray line outlines low Fe, HNLC biome samples from the N. Pacific.

also frequently dominate in coastal sites where trace metal concentrations can vary greatly (Bruland et al., 2001; Johnson et al., 2001).

Clades II, III and X were most commonly found at low latitude, open ocean sites (Figure 3) typified by significantly warmer temperatures and lower macronutrient levels than where clades I and IV dominate (Figures 4 and 6). Clade II in particular was the most ubiquitous clade, but not the most abundant (Supplementary Table S3), likely because it most often occurs in the open ocean where total Synechococcus is less abundant. This may explain why LSA networks showed positive relationships between clade II and $\mathrm{PO}_{4}^{3-}$ and $\mathrm{NO}_{3}^{-}$(Supplementary Figure S4) while clade II was negatively correlated to $\mathrm{PO}_{4}^{3-}$ by Spearman correlation, a non-linear statistic (Figure 4). Spearman correlations suggested that clade II most often occurred in oligotrophic waters while LSA networks highlight that when clade

II is detected its abundance increases with higher nutrient availability (confirmed by linear regression of only samples where clade II was found, $P<0.05$ ).

Our data show that clade II is the dominant openocean ecotype (Figure 3). This agrees with smallerscale quantitative surveys and clone libraries and analysis of global metagenomic data sets (Ferris and Palenik, 1998; Fuller et al., 2003, 2006; Zwirglmaier et al., 2007; Huang et al., 2011; Mazard et al., 2012a) but differs from a previous global survey where clade II was not detected in many open-ocean stations and rather was suggested to be a tropical/subtropical coastal/shelf ecotype (Zwirglmaier et al., 2007, 2008). This latter survey employed $16 \mathrm{~S}$ rDNA dot-blot probing methods for detection and it is possible that the discrepancy is due to that particular probe not capturing the full diversity of natural populations of clade II. In addition, clade $\mathrm{X}$ frequently co-occurs with clades II and III in warm, oligotrophic waters (Figures 3 and $4 \mathrm{a}$ ); it was detected at $78 \%$ of sites where both clades II and III occur or $44 \%$ of sites where either clade II or III is found. Clades III and X were generally less abundant and prevalent than clade II, and clade III was the least abundant of the three clades in this group (Figure 3, Supplementary Table S3). While the representative clade III strain, WH8102, has historically been considered as the type strain for the oligotrophic ocean (Palenik et al., 2006; Zwirglmaier et al., 2008), we show that clade II is in fact the dominant clade in waters of the largest marine biome and suggest that future studies focus on type strain(s) from clade II.

Clades CRD1 and CRD2, which are newly enumerated with our assays, were mostly restricted to tropical/subtropical upwelling waters (that is, the Costa Rica Dome, equatorial upwelling and the Benguela upwelling; Figure 3, Supplementary Figure S3). At these upwelling sites, they reached high abundances, with clade CRD1 showing the highest mean and maximum $\left(1.1 \times 10^{6}\right.$ cells $\left.\mathrm{ml}^{-1}\right)$ abundances of all clades (Supplementary Table S3). Accordingly, clades CRD1 and CRD2 had somewhat higher nutrient means than those of the other warm water clades II, III and X (Figure 6; Supplementary Figure S5), and clade CRD1 had a positive relationship to $\mathrm{PO}_{4}^{3-}$ in LSA networks (Supplementary Figure S4). It is noteworthy that clade CRD2 but not CRD1 was positively correlated to temperature (Figure 4b). This probably reflects the fact that clade CRD2 was found at low latitude sites only, while clade CRD1 was found at low latitude stations as well as few cold water sites in the subarctic North Pacific.

Among the predominantly warm water clades (II, III, X, CRD1 and CRD2) that were all detected in samples where $\mathrm{Fe}$ was measured concurrently (Supplementary Figure S1), clades CRD1 and CRD2 were found at sites with noticeably lower Fe levels (Figure 6c) and fittingly were negatively correlated with $\mathrm{Fe}$ (Figure 4b). In particular, clade CRD2 exhibited a statistically lower $\mathrm{Fe}$ range than 

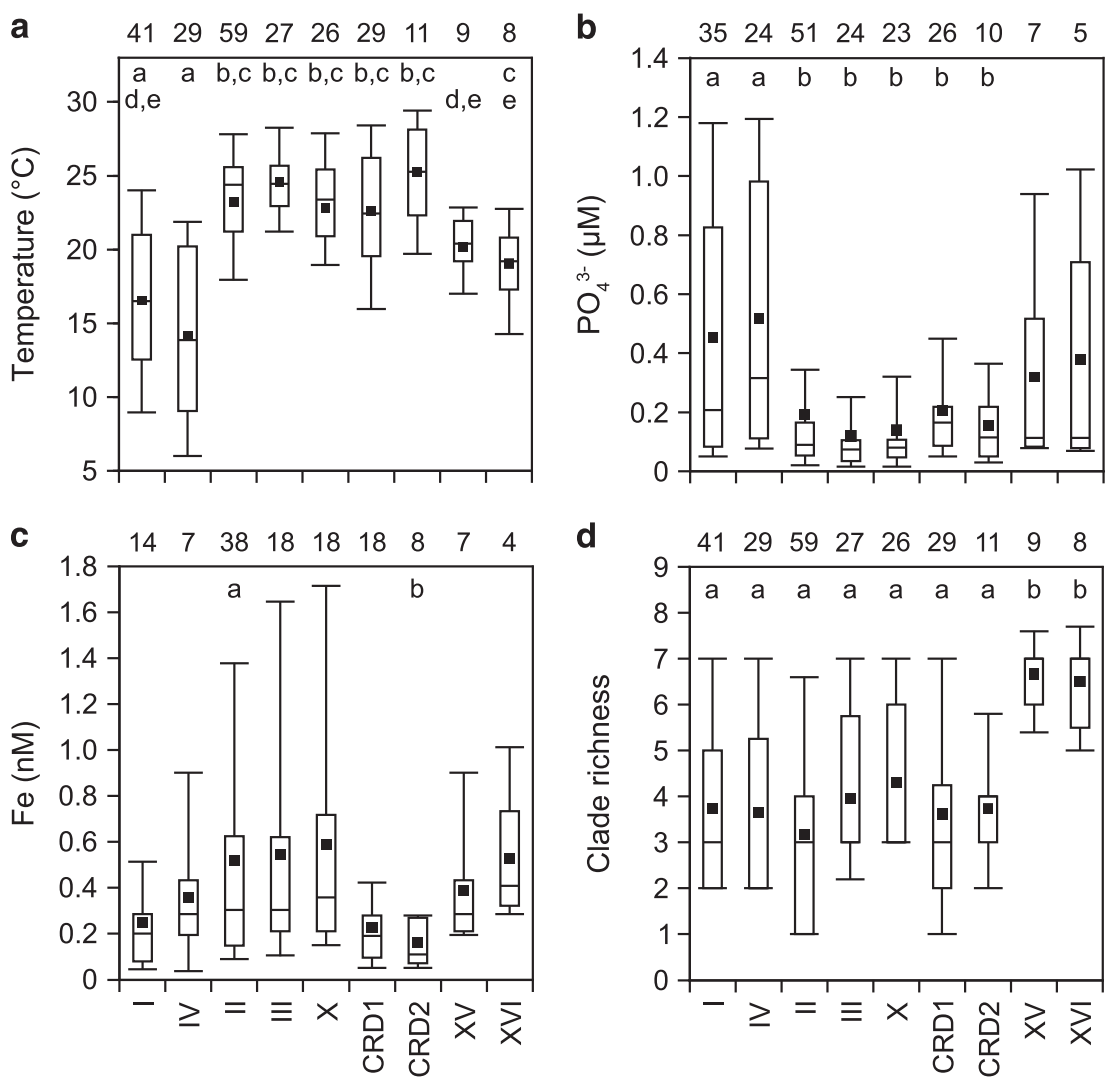

Figure 6 Box and whisker diagrams of the environmental conditions and clade richness (number of clades detected) of surface samples where each clade was detected. (a) Temperature, (b) $\mathrm{PO}_{4}^{3-}$ concentrations, (c) Fe concentrations and (d) clade richness. The box shows the $25-75 \%$ range, the whiskers show the $10-90 \%$ range, the bar shows the median and the square symbol shows the mean. Numbers at the top indicate the number of sites for which that clade was detected and the environmental parameter was measured. Letters above bars indicate the level of significance in pairwise comparisons of means. Clades that do not share letters have means that are significantly different from each other; clades with the same letter have means that are not significantly different from each other, and clades without letters have means that are not significantly different from any other clade (pairwise $t$-tests, $P<0.05$ ). Box plots for $\mathrm{NO}_{3}^{-}$were similar to those of $\mathrm{PO}_{4}^{3-}$ (Supplementary Figure S5).

clade II, another predominantly warm-water clade (Figure 6c). Low Fe was also significantly correlated to the distinct clustering of samples dominated by clades CRD1 and CRD2 (Figure 5b). Thus, these clades appear to be specifically adapted to low Fe habitats in comparison with clades II, III and X, which otherwise have comparable temperature and nutrient ranges (Figure 6).

Consistent with a low Fe niche for clades CRD1 and CRD2 is the fact that these clades dominate at sites in the Equatorial Pacific previously identified as HNLC oceanic regions where low Fe availability limits phytoplankton growth (Martin et al., 1991; Coale et al., 1996; Fung et al., 2000). Specifically clades CRD1 and CRD2 dominate at equatorial sites previously described as HNLC (Martin et al., 1991; Fung et al., 2000) in the Western Pacific (near $180^{\circ} \mathrm{W}$ ) while clade II dominates in adjacent gyre waters (Figure 3) and there is a clear transition in dominance from clade II to CRD1 on the transect going directly south of the Hawaiian Islands (Figures 2 and 3 ) in parallel with a decrease in Fe away from the islands (measured on a different cruise along this same transect; Supplementary
Figure S6). Although Fe was not measured for North Pacific samples, clade CRD1 was also abundant (up to $6 \times 10^{4}$ cells $\mathrm{ml}^{-1}$ ) at $\sim 40{ }^{\circ} \mathrm{N}$ (Figures 2 and 3 , Supplementary Figure S3), in the subarctic North Pacific HNLC region (Fung et al., 2000). Interestingly, many of the sites where clade CRD2 was found are also regions overlying oxygen minimum zones with elevated Co (Noble et al., 2012; Ahlgren et al., 2014), suggesting that high Co and low Fe availability may influence this clade's habitat range in tandem (Ahlgren et al., 2014). However, more data are needed to determine this.

Fe availability is known to limit total phytoplankton abundance in HNLC regions (Boyd et al., 2007) and some larger phytoplankton species are adapted to low Fe conditions (Marchetti et al., 2006). Two Prochlorococcus clades, HNLC1 and HNLC2, have been observed in low Fe HNLC habitats (Rusch et al., 2010; West et al., 2011); these low Fe Synechococcus clades have therefore emerged in parallel to similarly adapted HNLC Prochlorococcus clades. More broadly, our results complement genomic and physiological work that indicate trace metals are important in shaping the evolution 
and ecology of phytoplankton ecotypes (Mann et al., 2002; Palenik et al., 2006; Rivers et al., 2009; Scanlan et al., 2009; Stuart et al., 2009; Ahlgren et al., 2014). Different clades are known to contain different complements of Fe stress-related genes, suggesting that the presence or absence of these genes could give cells an advantage under $\mathrm{Fe}$ stress (Palenik et al., 2006; Rivers et al., 2009; Scanlan et al., 2009). It will be interesting to see what Fe-related gene clades CRD1 and CRD2 possess and if they exhibit similar genomic signatures of low $\mathrm{Fe}$ adaptation to those in Prochlorococcus HNLC clades, namely fewer genes encoding Fe-binding proteins. Unfortunately, there are no published genomes of clade CRD1 strains, and there are no cultured isolates of clade CRD2.

The last group of clades, XV and XVI, were neither ubiquitous nor particularly abundant (Figure 3, Supplementary Figure S3, Supplementary Table S3). They were only detected at samples belonging to the 'transitional' non-metric multidimensional scaling cluster (Figure 5) that exhibit intermediate temperatures, nutrients and Fe levels (Figure 6). These sites also had significantly higher clade richness (Figure 6d) and often occurred near the junctions of the other three biomes (for example, in waters between Australia and New Zealand, Supplementary Figure S3). This evidence suggests that clades XV and XVI are adapted to life in marine ecotones-regions at the edges or transitions of other biomes that are typified by intermediate environmental conditions and higher diversity. Clades XV and XVI have also been shown to occupy subsurface waters elsewhere (Ahlgren et al., 2014; GutierrezRodriguez et al., 2014), so perhaps higher mixing in ecotone sites brings them to the surface and explains why they were rarely detected in surface waters. In fact, in the Sargasso Sea, clades XV and XVI were present through the water column at the onset of water column stratification following winter deep mixing (Ahlgren and Rocap, 2006).

Overall, our findings demonstrate coherent biogeographic patterns in the distributions of the major Synechococcus clades. Notably, several clades share similar environmental niches that are broadly defined by temperature, macronutrient and dissolved $\mathrm{Fe}$ concentrations. We confirm the dominance of clades I and IV in cold, mesotrophic waters (Zwirglmaier et al., 2008; Tai and Palenik, 2009; Ahlgren and Rocap, 2012); but more importantly we reveal the niches of remaining clades that were previously undetermined or poorly defined (II, X, XV, XVI, CRD1 and CRD2). In particular, this study makes significant advances to Synechococcus clade ecology by establishing that clade II is the dominant ecotype in the world's oceans; clade $\mathrm{X}$ often co-occurs with clade II in warm, oligotrophic habitats; clades CRD1 and CRD2 dominate in low Fe habitats; and less abundant clades XV and XVI are often found at the transitions of major biomes.

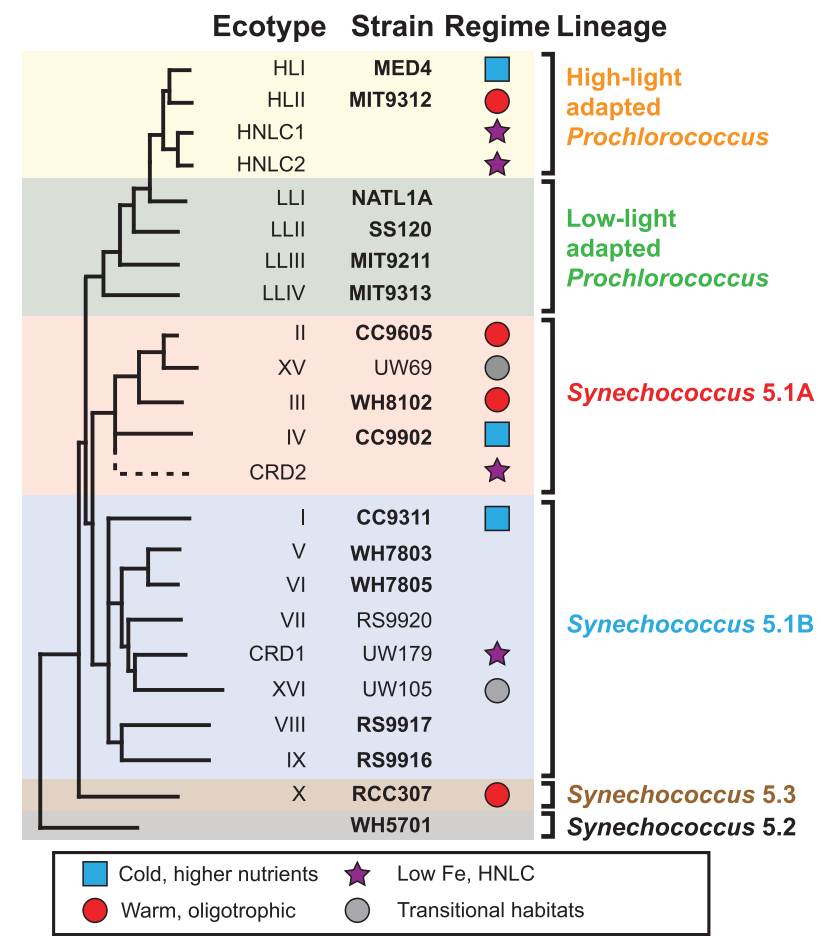

Figure 7 The phylogeny of Prochlorococcus and Synechococcus ecotypes, representative strains, and the oceanic regimes they occupy. The regimes that ecotypes occupy are paraphyletic, consistent with a pattern of parallel evolution whereby clades have independently adapted to similar habitats. The schematic tree depicted is supported by congruent concatenated core gene phylogenies (Ahlgren and Rocap, 2012; Mazard et al., 2012a) and phylogenomic analysis of $>1100$ core genes (Dufresne et al., 2008). Clade CRD2 groups closely with 5.1 A strains based on ITS phylogeny and is provisionally assigned to this subcluster (dashed line). Representative strains that have had their genomes sequenced are shown in bold.

\section{Evolutionary relationships of co-occurring clades}

Having elucidated the niches of several major Synechococcus clades, we examined the evolutionary relatedness of co-occurring clades and found that many of the clades that share similar niches are not closely related within the marine Synechococcus group (Figure 7). Although the form genus Synechococcus is dispersed polyphyletically across the cyanobacterial tree, most marine Synechococcus clades belong to the larger phylogenetic cluster 5.1 that comprises two distinct subgroups of clades, labeled 5.1 A (II, III, IV and XV) and 5.1B (I, V, VI, VII, VIII, IX, XVI and CRD1). Clade X belongs to a third related lineage, cluster 5.3 (Dufresne et al., 2008; Scanlan et al., 2009; Huang et al., 2011; Mazard et al., 2012a). Thus, clades I and IV, which co-occur in colder, nutrient-rich waters, belong to different lineages within cluster 5.1. Similarly, clades XV and XVI, which co-occur in transitional waters, also belong to different subclusters. Likewise, although both clades II and III are found in subcluster $5.1 \mathrm{~A}$, they share a similar environmental niche with clade $\mathrm{X}$, which belongs to a separate cluster (5.3). Clades CRD1 and CRD2 that are prevalent in low $\mathrm{Fe}$ waters are likely a fourth 
example. Clade CRD1 is a member of subcluster 5.1B (Ahlgren and Rocap, 2012; Mazard et al., 2012a), while ITS phylogeny suggests clade CRD2 is closely related to 5.1 A clades (Huang et al., 2011; Ahlgren and Rocap, 2012).

Therefore clades within each of the phylogenetically defined subclusters 5.1 A and 5.1B do not share a single, cohesive habitat or niche. It had been previously suggested that clades within the same subcluster have similar ecological strategies because of their shared evolutionary history, with $5.1 \mathrm{~A}$ clades described as 'oligotrophs/specialists' and 5.1B clades as 'generalists/opportunists' partly because 5.1 A strains have significantly fewer enzymes that sense and respond to the environment than 5.1B strains (Palenik et al., 2006; Dufresne et al., 2008). Our data suggest that Synechococcus clades occupying the same regimes have independently arisen multiple times and represent examples of convergent or parallel evolution. We herein use the latter term since it refers to convergent evolution that has occurred among closely related organisms (Freeman and Herron, 1998).

Parallel evolution also describes the overall pattern of ecotype radiation of both Prochlorococcus and Synechococcus together. Ecotypes that occupy the three major biomes have emerged from within at least four major lineages within the marine picocyanobacteria (Figure 7). Specifically, ecotypes that dominate in low-Fe, HNLC waters have evolved in both Synechococcus and Prochlorococcus. Similarly, cold- and warm-adapted ecotypes that partition the high or low latitude portions of the open-ocean gyres have emerged independently in both genera. Interestingly, the shift from warm-water Synechococcus clades (II, III and X) to cold-water clades (I and IV) occurs at $\sim 21^{\circ} \mathrm{C}$ in the open ocean, similar to the thresholds for the shifts in dominance of warmadapted HLII to cold-adapted HLI Prochlorococcus ecotypes (Supplementary Figure S7; Johnson et al., 2006).

Parallel evolution of ecotypes may be facilitated by the horizontal transfer of adaptive genes, from both other marine bacteria and among picocyanobacteria (Kettler et al., 2007; Dufresne et al., 2008; Scanlan et al., 2009; Zhaxybayeva et al., 2009). Such gene transfer is at least partially mediated by cyanophage, which can cross-infect multiple Prochlorococcus ecotypes and Synechococcus clades (Sullivan et al., 2006). Genome comparisons within the picocyanobacteria reveal paraphyletic distributions of potentially adaptive genes as a result of horizontal gene transfer (Dufresne et al., 2008; Scanlan et al., 2009; Zhaxybayeva et al., 2009). For example, phycobilisome genes appear to have been horizontally transferred between Synechococcus clades, resulting in a diversity of pigment types that are shared across lineages (Six et al., 2007; Everroad and Wood, 2012). Similarly, the distribution of phosphate utilization genes among Prochlorococcus strains is better explained by $\mathrm{P}$ availability in the oceanic basin from which they were isolated than their core-gene phylogeny (Martiny et al., 2006). The recent discovery of nitrate utilization in Prochlorococcus is another example where gene acquisition occurred independently across ecotypes (Berube et al., 2015). In addition to sharing genes across ecotypes that are important for adaptation to particular niches, cooccurring ecotypes could also possess distinct genomic changes (as a result of horizontal gene transfer, de novo mutation or gene loss) that allow for adaptation to the same environment, but by different mechanisms. Since currently only the genomes of one or two strains have been sequenced within each Synechococcus clade, it is not possible to assess intra- vs inter-clade genomic differences (Zhaxybayeva et al., 2009). As more genomes are sequenced, it will be feasible to investigate how distribution of specific accessory genes may confer adaptation to their niches to understand the mechanisms behind this observed parallel evolution. In particular, it will be intriguing to determine whether low Fe Synechococcus CRD1 and CRD2 identified herein (for which there are currently no genomes publically available) share adaptations observed in low Fe, HNLC Prochlorococcus ecotypes (Rusch et al., 2010).

Recently described ecotypes in SAR11, an abundant lineage of pelagic Alphaproteobacteria, also exhibit parallel evolution (Vergin et al., 2013). SAR11 ecotypes occupy distinct niches according to depth and season but deep and surface types are paraphyletic rather than monophyletic. Thus, rather than a model of evolution whereby invasion of niches occurs in a sequential manner, ecotypes that occupy deep or shallow portions of the water column appear to have independently arisen multiple times within different major lineages of SAR11. Parallel evolution of ecotypes may prove to be a common theme for marine microbial populations.

\section{Ecological significance of co-occurring ecotypes}

Co-occurrence of closely related ecotypes initially seems unexpected as outlined in the classic "paradox of the plankton' argument, which suggests competition for the same resources in a relatively well-mixed environment should produce a small number of winning taxa (Hutchinson, 1961). Other bottom-up factors likely differentiate the niches of co-occurring clades such as the ability to use organic $\mathrm{N}$ and $\mathrm{P}$ or differences in the ratio at which multiple nutrients are utilized (Roy and Chattopadhyay, 2007). Topdown pressures such as grazing (Apple et al., 2011) and virus infection (Suttle, 2007) or 'lateral' mechanisms such as commensalism (Morris et al., 2012) and allelopathy (Paz-Yepes et al., 2013) could also contribute to the maintenance of multiple ecotypes. Regardless of the mechanism for co-existence, a potential consequence of the parallel evolution of cooccurring populations is a level of functional redundancy in the community that may influence 
overall stability (Tilman and Downing, 1994). Multiple ecotypes within a biome may provide a larger pool of genetic variants from which adaptive strains could be selected and the potential loss of one ecotype within a biome could be buffered by the persistence of the other member(s). Thus cooccurring ecotypes perhaps create the potential for resiliency within marine microbial communities in the face of impending climate change.

\section{Conflict of Interest}

The authors declare no conflict of interest.

\section{Acknowledgements}

We thank the captains and crews of the R/Vs Barkley Star, Kilo Moana, Knorr, Oceanus, Seward Johnson, Seawatch and Thomas G. Thompson as well as the chief scientists for these cruises: Ginger Armbrust, Steven Emerson, Zackary Johnson, Rick Keil, Joe Montoya, Rob Olson, Paul Quay, Jon Zehr and Erik Zinser. We thank Emily Nahas Reistetter for assistance with qPCR assays. This work was funded by NSF research grants OCE-0825922 to Eric Webb, OCE-0352190 and OCE-0723866 to Gabrielle Rocap, OCE-0623499 to Jim Moffet, and OCE-1031271 to Mak Saito and also grant 3782 from the Gordon and Betty Moore Foundation to Mak Saito. We also acknowledge funding from the Lamont Doherty Earth Observatory Marie Tharp Fellowship to Jill Sohm, support from a National Defense Science and Engineering graduate fellowship and the Moore Foundation Marine Microbial Initiative to Nathan Ahlgren, and the Mary Gates Research Scholarship to Zachary Thomson.

\section{References}

Ahlgren NA, Rocap G. (2006). Culture isolation and culture-independent clone libraries reveal new marine Synechococcus ecotypes with distinctive light and N physiologies. Appl Environ Microbiol 72: 7193-7204.

Ahlgren NA, Rocap G. (2012). Diversity and distribution of marine Synechococcus: multiple gene phylogenies for consensus classification and development of qPCR assays for sensitive measurement of clades in the ocean. Front Microbiol 3: 213.

Ahlgren NA, Noble AE, Patton AP, Roache-Johnson K, Jackson L, Robinson D et al. (2014). The unique trace metal and mixed layer conditions of the Costa Rica upwelling dome support a distinct and dense community of Synechococcus. Limnol Oceanogr 59: 2166-2184.

Apple JK, Strom SL, Palenik B, Brahamsha B. (2011). Variability in protist grazing and growth rates on different marin Synechococcus isolates. Appl Environ Microbiol 77: 3074-3084.

Benjamini Y, Hochberg Y. (1995). Controlling the false discovery rate: a practical and powerful approach to multiple testing. JR Stat Soc Series B Stat Methodol 57: 289-300.

Berube PM, Biller SJ, Kent AG, Berta-Thompson JW, Roggensack SE, Roache-Johnson KH et al. (2015).
Physiology and evolution of nitrate acquisition in Prochlorococcus. ISME J 9: 1195-1207.

Boyd PW, Jickells T, Law CS, Blain S, Boyle EA, Buesseler $\mathrm{KO}$ et al. (2007). Mesoscale iron enrichment experiments 1993-2005: synthesis and future directions. Science 315: 612-617.

Bruland KW, Rue EL, Smith GJ. (2001). Iron and macronutrients in California coastal upwelling regimes: Implications for diatoms blooms. Limnol Oceanogr 46: 1661-1674.

Chappell PD, Moffett JW, Hynes AM, Webb EA. (2012). Molecular evidence of iron limitation and availability in the global diazotroph Trichodesmium. ISME $J \mathbf{6}$ : 1728-1739.

Choi DH, Noh JH. (2009). Phylogenetic diversity of Synechococcus strains isolated from the East China Sea and the East Sea. FEMS Microbiology Ecology 69: 439-448.

Coale KH, Johnson KS, Fitzwater SE, Gordon RM, Tanner S, Chavez FP et al. (1996). A massive phytoplankton bloom induced by an ecosystem-scale iron fertilization experiment in the equatorial Pacific Ocean. Nature 383: 495-501.

Coleman M, Chisholm SW. (2007). Code and context: Prochlorococcus as a model for cross scale biology. Trends Microbiol 15: 398-407.

Dean RB, Dixon WJ. (1951). Simplified statistics for small numbers of obesrvations. Anal Chem 23: $636-638$.

Dufresne A, Ostrowski M, Scanlan DJ, Garczarek L, Mazard S, Palenik BP et al. (2008). Unraveling the genomic mosaic of a ubiquitous genus of marine cyanobacteria. Genome Biol 9: R90.

Everroad RC, Wood AM. (2012). Phycoerythrin evolution and diversification of spectral phenotype in marine Synechococcus and related picocyanobacteria. Mol Phylogenet Evol 64: 381-392.

Ferris MJ, Palenik B. (1998). Niche adaptation in ocean cyanobacteria. Nature 396: 226-228.

Field CB, Behrenfeld MJ, Randerson JT, Falkowski P. (1998). Primary production of the biosphere: Integrating terrestrial and oceanic components. Science 281: 237-240.

Flombaum P, Gallegos JL, Gordillo RA, Rincon J, Zabala LL, Jiao $\mathrm{N}$ et al. (2013). Present and future global distributions of the marine Cyanobacteria Prochlorococcus and Synechococcus. Proc Natl Acad Sci USA 10: 9824-9829.

Freeman S, Herron JC. (1998). Evolutionary Analysis. Prentice HallUpper Saddle River, NJ.

Fuller NJ, Marie D, Partensky F, Vaulot D, Post AF, Scanlan DJ. (2003). Clade-specific $16 \mathrm{~S}$ ribosomal DNA oligonucleotides reveal the predominance of a single marine Synechococcus clade throughout a stratified water column in the Red Sea. Appl Environ Microbiol 69: $2430-2443$.

Fuller NJ, Tarran GA, Yallop M, Orcutt KM, Scanlan DJ. (2006). Molecular analysis of picocyanobacterial community structure along an Arabian Sea transect reveals distinct spatial separation of lineages. Limnol Oceanogr 51: 2515-2526.

Fung IY, Meyn SK, Tegen I, Doney SC, John JG, Bishop JKB. (2000). Iron supply and demand in the upper ocean. Glob Biogeochem Cycles 14: 281-295.

Gutierrez-Rodriguez A, Slack G, Daniels EF, Selph KE, Palenik B, Landry MR. (2014). Fine spatial structure of genetically distinct picocyanobacterial populations 
across environmental gradients in the Costa Rica Dome. Limnol Oceanogr 59: 705-723.

Huang S, Wilhelm SW, Harvey HR, Taylor K, Jiao N, Chen F. (2011). Novel lineages of Prochlorococcus and Synechococcus in the global oceans. ISME $J \mathbf{6}$ : 285-297.

Hutchinson GE. (1961). The paradox of the plankton. Am Nat 95: 137-145.

Jardillier L, Zubkov MV, Pearman J, Scanlan DJ. (2010). Significant $\mathrm{CO}_{2}$ fixation by small prymnesiophytes in the subtropical and tropical northeast Atlantic Ocean. ISME J 4: 1180-1192.

Johnson KS, Chavez FP, Elrod VA, Fitzwater SE, Pennington JT, Buck KR et al. (2001). The annual cycle of iron and the biological response in central California coastal waters. Geophys Res Lett 28: 1247-1250.

Johnson ZI, Zinser ER, Coe A, McNulty NP, Woodward EMS, Chisholm SW. (2006). Niche partitioning among Prochlorococcus ecotypes along ocean-scale environmental gradients. Science 311: 1737-1740.

Kettler GC, Martiny AC, Huang K, Zucker J, Coleman ML, Rodrigue S et al. (2007). Patterns and implications of gene gain and loss in the evolution of Prochlorococcus. PLoS Genet 3: 2515-2528.

Malmstrom RR, Rodrigue S, Huang KH, Kelly L, Kern SE, Thompson A et al. (2012). Ecology of uncultured Prochlorococcus clades revealed through single-cell genomics and biogeographic analysis. ISME $J$ 7: 184-198.

Mann EL, Ahlgren NA, Moffett JW, Chisholm SW. (2002). Copper toxicity and cyanobacteria ecology in the Sargasso Sea. Limnol Oceanogr 47: 976-988.

Marchetti A, Maldonado MT, Lane ES, Harrison PJ. (2006). Iron requirements of the pennate diatom Pseudonitzschia: Comparison of oceanic (high-nitrate, lowchlorophyll waters) and coastal species. Limnol Oceanogr 51: 2092-2101.

Marie D, Simon N, Vaulot D. (2005). Phytoplankton cell counting by flow cytometry. In: Anderson RA (ed) Algal Culturing Techniques. Academic Press: Burlington, MA, USA, pp 253-268.

Martin JH, Gordon RM, Fitzwater SE. (1991). The case for iron. Limnol Oceanogr 36: 1793-1802.

Martiny AC, Coleman ML, Chisholm SW. (2006). Phopshate acquisition genes in Prochlrococcus ecotypes: Evidence for genome-wide adaptation. Proc Natl Acad Sci USA 103: 12552-12557.

Martiny AC, Tai APK, Veneziano D, Primeau F, Chisholm SW. (2009). Taxonomic resolution, ecotypes and the biogeography of Prochlorococcus. Environ Microbiol 11: 823-832.

Mazard S, Ostrowski M, Partensky F, Scanlan DJ. (2012a). Multi-locus sequence analysis, taxonomic resolution and biogeography of marine Synechococcus. Environ Microbiol 14: 372-386.

Mazard S, Wilson WH, Scanlan DJ. (2012b). Dissection the physiological response to phosphorus stress in marine Synechococcus isolates (CYANOPHYCEAE). J Phycol 48: 94-105.

Mella-Flores D, Mazard S, Humily F, Partensky F, Mahe F, Bariat L et al. (2011). Is the distribution of Prochlorococcus and Synechococcus ecotypes in the Mediterranean Sea affected by global warming? Biogeosci Discuss 8: 4281-4330.

Moore LR, Rocap G, Chisholm SW. (1998). Physiology and molecular phylogeny of coexisting Prochlorococcus ecotypes. Nature 393: 464-467.
Moore LR, Post AF, Rocap G, Chisholm SW. (2002). Utilization of different nitrogen sources by the marine cyanobacteria Prochlorococcus and Synechococcus. Limnol Oceanogr 47: 989-996.

Moore LR, Ostrowski M, Scanlan DJ, Feren K, Sweetsir T. (2005). Ecotypic variation in phosphorus acquisition mechanisms within marine picocyanobacteria. Aquat Microb Ecol 39: 257-269.

Morris JJ, Lenski RE, Zinser ER. (2012). The black queen hypothesis: evolution of dependencies through adaptive gene loss. mBio 3: e00036-12.

Noble AE, Lamborg CH, Ohnemus DC, Lam PJ, Goepfert TJ, Measures C et al. (2012). Basin-scale inputs of cobalt, iron and manganese from the Benguela-Angola front to the South Atlantic Ocean. Limnol Oceanogr 57: 989-1010.

Oksanen J, Blanchet FG, Kindt R, Legendre P, Minchin PR, O'Hara RB et al. (2012). vegan: Community Ecology Package 2.0-3.

Paerl RW, Foster RA, Jenkins BD, Montoya JP, Zehr JP. (2008). Phylogenetic diversity of cyanobacterial narB genes from various marine habitats. Environ Microbiol 10: $3377-3387$.

Palenik B. (2001). Chromatic adaptation in marine Synechococcus strains. Appl Environ Microbiol 67: 991-994.

Palenik B, Ren QH, Dupont CL, Myers GS, Heidelberg JF, Badger JH et al. (2006). Genome sequence of Synechococcus CC9311: Insights into adaptation to a coastal environment. Proc Natl Acad Sci USA 103: 13555-13559.

Paz-Yepes J, Brahamsha B, Palenik B. (2013). Role of a Microcin-C-like biosynthetic gene cluster in allelopathic interactions in marine Synechococcus. Proc Natl Acad Sci USA 110: 12030-12035.

Pittera J, Humily F, Thorel M, Grulois D, Garczarek L, Six C. (2014). Connecting thermal physiology and latitudinal niche partitioning in marine Synechococcus. ISME J 8: 1221-1236.

Rivers AR, Jakuba RW, Webb EA. (2009). Iron stress genes in marine Synechococcus and the development of a flow cytometric iron stress assay. Environ Microbiol 11: 382-396.

Rocap G, Distel DL, Waterbury JB, Chisholm SW. (2002). Resolution of Prochlorococcus and Synechococcus ecotypes by using $16 \mathrm{~S}-23 \mathrm{~S}$ ribosomal DNA internal transcribed spacer sequences. Appl Environ Microbiol 68: 1180-1191.

Roy S, Chattopadhyay J. (2007). Towards a resolution of the paradox of the plankton': A brief overview of the proposed mechanisms. Ecol Complex 4: 26-33.

Ruan Q, Dutta D, Schwalbach MS, Steele JA, Fuhrman JA, Sun F. (2006). Local similarity analysis reveals unique associations among marine bacterioplankton species and environmental factors. Bioinformatics 22: 2532-2538.

Rusch DB, Martiny AC, Dupont CL, Halpern AL, Venter JC. (2010). Characterization of Prochlorococcus clades from iron-depleted oceanic regions. Proc Natl Acad Sci USA 107: 16184-16189.

Scanlan DJ, Ostrowski M, Mazard S, Dufresne A, Garczarek L, Hess WR et al. (2009). Ecological genomics of marine Picocyanobacteria. Microbiol Mol Biol Rev 73: 249-299.

Six C, Thomas J, Garczarek L, Ostrowski M, Dufresne A, Blot $\mathrm{N}$ et al. (2007). Diversity and evolution of phycobilisomes in marine Synechococcus spp.: a comparative genomics study. Genome Biol 8: R259. 
Strickland JDH, Parsons TR. (1968). A Practical Handbook of Seawater Analysis. Fisheries Resource Board: Ottawa, Canada.

Stuart RK, Dupont CL, Johnson DA, Paulsen IT, Palenik B. (2009). Coastal strains of marine Synechococcus species exhibit increased tolerance to copper shock and a distinctive transcriptional response relative to those of open-ocean strains. Appl Environ Microbiol 75: $5047-5057$

Sullivan MB, Lindell D, Lee JA, Thompson LR, Bielawski JP, Chisholm SW. (2006). Prevalence and evolution of core photosystem II genes in marine cyanobacterial viruses and their hosts. Plos One 4: e234.

Suttle CA. (2007). Marine viruses - major players in the global ecosystem. Nat Rev Microbiol 5: 801-812.

Tai V, Palenik B. (2009). Temporal variation of Synechococcus clades at a coastal Pacific Ocean monitoring site. ISME J 3: 903-915.

Tilman D, Downing JA. (1994). Biodiversity and stability in grasslands. Nature 367: 363-365.

Toledo G, Palenik B. (1997). Synechococcus diversity in the California current as seen by RNA polymerase (rpoC1) gene sequences of isolated strains. Appl Environ Microbiol 63: 4298-4303.

Vergin KL, Beszteri B, Monier A, Thrash JC, Kilpert F, Worden AZ et al. (2013). High-resolution SAR11 ecotype dynamics at the Bermuda Atlantic Time- series Study site by phylogenetic placement of pyrosequences. ISME J 7: 1322-1332.

Waterbury JB, Watson SW, Valois FW, Franks DG. (1986). Biological and ecological characterization of the marine unicellular cyanobacterium Synechococcus. Can Bull Fish Aquat Sci 214: 71-120.

West NJ, Lebaron P, Strutton PG, Suzuki MT. (2011). A novel clade of Prochlorococcus found in high nutrient low chlorophyll waters in the South and Equatorial Pacific Ocean. ISME J 5: 933-944.

Zhaxybayeva O, Doolittle WF, Thane Papke F, Peter Gogarten JG. (2009). Intertwined evolutionary histories of marine Synechococcus and Prochlorococcus marinus. Genome Biol Evol 1: 325-339.

Zinser ER, Johnson ZI, Coe A, Karaca E, Veneziano D, Chisholm SW. (2007). Influence of light and temperature on Prochlorococcus ecotype distributions in the Atlantic Ocean. Limnol Oceanogr 52: 2205-2220.

Zwirglmaier K, Heywood JL, Chamberlain K, Woodward EMS, Zubkov MV, Scanlan DJ. (2007). Basin-scale distribution patterns lineages in the Atlantic Ocean. Environ Microbiol 9: 1278-1290.

Zwirglmaier K, Jardillier L, Ostrowski M, Mazard S, Garczarek L, Vaulot D et al. (2008). Global phylogeography of marine Synechococcus and Prochlorococcus reveals a distinct partitioning of lineages among oceanic biomes. Environ Microbiol 10: 147-161.

Supplementary Information accompanies this paper on The ISME Journal website (http://www.nature.com/ismej) 